Published in final edited form as:

Cochrane Database Syst Rev. ; (2): CD006539. doi:10.1002/14651858.CD006539.pub2.

\title{
Neuroprotection for treatment of glaucoma in adults
}

\author{
Dayse F Sena ${ }^{1}$, Kanchan Ramchand ${ }^{2}$, and Kristina Lindsley ${ }^{3}$ \\ ${ }^{1}$ Massachusetts Eye and Ear Infirmary, Massachusetts, Boston, USA \\ ${ }^{2}$ Massachusetts, Waltham, USA \\ ${ }^{3}$ Center for Clinical Trials, Johns Hopkins University Bloomberg School of Public Health, \\ Maryland, Baltimore, USA
}

\begin{abstract}
Background-Glaucoma is a heterogeneous group of conditions involving progressive damage to the optic nerve, deterioration of retinal ganglion cells and ultimately visual field loss. It is a leading cause of blindness worldwide. Open angle glaucoma (OAG), the commonest form of glaucoma, is a chronic condition that may or may not present with increased intraocular pressure (IOP). Neuroprotection for glaucoma refers to any intervention intended to prevent optic nerve damage or cell death. The treatment can target extracellular factors such as reducing IOP, or cellular factors derived from the optic nerve itself such as blocking intracellular death signals.
\end{abstract}

Objectives-The objective of this review was to systematically examine the evidence regarding the effectiveness of neuroprotective agents, either topical or oral, for slowing the progression of OAG in adults.

Search methods-We searched the Cochrane Central Register of Controlled Trials (CENTRAL) (which contains the Cochrane Eyes and Vision Group Trials Register) (The Cochrane Library, Issue 4, 2009), MEDLINE (January 1960 to January 2010), EMBASE (January 1980 to January 2010), Latin American and Caribbean Literature on Health Sciences (LILACS) (January 1982 to January 2010) and ClinicalTrials.gov (http://clinicaltrials.gov). (5 January 2010).

Contact person: Dayse F Sena, Massachusetts Eye and Ear Infirmary, 243 Charles St, Connecting Building 703, Boston, Massachusetts, 02114, USA, dsena@partners.org, sena.dayse@gmail.com.

Contributions of authors

Conceiving the review: DS

Designing the review: DS, KR

Co-ordinating the review: DS

Data collection for the review

- Designing electronic search strategies: Cochrane Eyes and Vision Group editorial base

- Undertaking electronic searches: Cochrane Eyes and Vision Group editorial base

- $\quad$ Screening search results: DS, KR

- Organizing retrieval of papers: DS, KL

- Screening retrieved papers against inclusion criteria: DS, KR, KL

- $\quad$ Providing additional data about papers: DS

- Obtaining and screening data on unpublished studies: DS, KL

Data management for the review: DS, KL

Analysis of data: DS, KL

Writing the review: DS, KL

Declarations of interest

None known. 
There were no language or date restrictions in the search for trials. The electronic databases were last searched on 5 January 2010.

Selection criteria-This review was limited to randomized controlled trials (RCTs) in which topical or oral treatments were used to prevent retinal ganglion cell death. Our population of interest was adults with OAG. As the primary outcome for this review was the proportion of participants who developed any progression of visual field loss at five years post intervention, only trials with at least five years of follow-up were included.

Data collection and analysis-Two review authors independently reviewed titles and abstracts from the literature searches. Full text copies of relevant or potentially relevant studies were obtained and re-evaluated for inclusion. There were no trials identified for this review, thus we performed no data extraction or meta-analysis. Two studies comparing memantine to placebo are currently awaiting classification until additional study details are provided. Reasons for excluding studies from the review were documented.

Main results-In accordance with the selection criteria for inclusion, we identified no studies relevant for this review. The results of short-term trials and other studies are discussed in this review.

Authors' conclusions-Although neuroprotective agents are intended to act as pharmacological antagonists to prevent cell death, the evidence that they are effective in preventing retinal ganglion cell death, and thus preserving vision in patients with $\mathrm{OAG}$, has not been demonstrated. Long-term RCTs are needed to determine whether or not neuroprotective agents may be beneficial for individuals with OAG.

\section{Plain language summary}

\section{Neuroprotection for treatment of glaucoma in adults}

Glaucoma is a leading cause of blindness worldwide. It is classified as a group of conditions characterized by progressive damage to the optic nerve, deterioration of retinal ganglion cells and ultimately visual field loss. With regards to glaucoma, neuroprotection refers to any intervention intended to prevent optic nerve damage or cell death. The rationale for treatment is that by acting as pharmacological antagonists, neuroprotective agents will prevent optic nerve damage and cell death, thus preserving vision in patients with glaucoma. The purpose of this review was to examine the evidence for the effectiveness of neuroprotection for glaucoma. No relevant studies were identified, although short-term trials and other studies are discussed. At present there is insufficient evidence to conclude whether neuroprotective agents are effective for the treatment of glaucoma.

\section{Background}

\section{Description of the condition}

Glaucoma is part of a heterogeneous group of conditions with multiple etiologies. It is characterized by optic neuropathies that involve structural damage of the optic nerve, death of retinal ganglion cells (RGCs) and defects of the visual field. The optic nerve, formed by the clustering of axons from RGCs located in the ganglion cell layer of the retina, carries visual impulses from the eye to the brain (Gupta 1997). When optic nerve damage or deterioration causes the transfer of information to be disrupted, vision loss occurs.

There are two main categories of primary glaucoma: open angle glaucoma and closed angle glaucoma. Open angle glaucoma (OAG), the commonest form of glaucoma, is a chronic and progressive optic nerve disease that is likely to be affected by multiple genetic and environmental factors (Hauser 2006a; Hauser 2006b). Open angle glaucoma can be accompanied by increased intraocular pressure (IOP), as with primary open angle glaucoma 
(POAG), or normal IOP, as with normal tension glaucoma. Closed angle glaucoma tends to occur suddenly and is beyond the scope of this review.

Epidemiology-Glaucoma is the second leading cause of loss of vision in the world (Quigley 2006; Resnikoff 2004) and an increasingly important public health concern due to the aging world population. The World Health Organization (WHO) estimates that 105 million people have glaucoma worldwide and around five million are blind as a consequence (Osborne 2003; Quigley 2006).

Open angle glaucoma is the commonest form of glaucoma in Caucasian and African populations, whereas closed angle glaucoma is more common in Asian populations (Bonomi 2002; Tielsch 1991). In the United States, rates of POAG are reported to be four to five times greater in African-American populations compared to European-derived populations, with the rates for Mexican-Americans in between (Quigley 2001; Tielsch 1991). The prevalence of POAG in Chinese populations is reported to be similar to European-derived populations, but is greater in southern India populations compared to European-derived populations (Foster 2000; Ramakrishnan 2003). Primary open angle glaucoma is inherited as a complex trait although environmental factors may also contribute to the disease (Hunter 2005).

Ocular hypertension, or high IOP, is considered one of the main risk factors for the development of glaucoma, but is neither necessary nor sufficient to induce the neuropathy. Other risk factors for glaucoma include aging, positive family history of glaucoma in a first degree relative, central corneal thickness less than 555 microns, high myopia and migraine headaches ( Anderson 2003; Armaly 1980; Heijl 2002).

Presentation and diagnosis-Open angle glaucoma is usually asymptomatic in the early stages. In some cases the disease may go unnoticed until unrecoverable damage to the optic nerve causes peripheral visual field defects. Without treatment there is a gradual loss of vision over time, ultimately leading to irreversible blindness.

In some patients the degeneration of the optic nerve occurs even if the IOP is within the normal range. This is termed as normal or low tension glaucoma, and is thought to represent a subtype of adult onset OAG. The clinical appearance of the optic nerve in normal tension glaucoma and in primary optic neuropathies is very similar. The distinction between high tension glaucoma (HTG) and low tension glaucoma (LTG) is that patients with HTG present with an IOP of $21 \mathrm{mmHg}$ or more (Kamal 1998).

In addition to measuring IOP when testing for glaucoma, it is equally important to perform a visual field test and to visualize the optic nerve to establish the diagnosis of glaucoma. Measurements of the vertical cup/disc ratio, especially in relation to the optic disc size, may be useful in identifying potential cases of glaucoma (Garway-Heath 1998). In some patients, RGC death can clinically be detected by specific visual field loss (Schwartz 2000).

Treatment options-Early detection and treatment of glaucoma is critical as progression of the disease will result in permanent blindness (Shields 1996). Once peripheral or central vision is lost due to glaucoma, no form of treatment can ever restore it. Most treatment for glaucoma continues to be directed at reducing IOP and slowing the disease progression, although it is also known that for many patients the reduction of IOP by itself does not prevent optic nerve damage or visual field loss. Furthermore, studies have shown that the loss of RGCs continues despite lowering IOP (Brubaker 1996; Cockburn 1983). Thus, interventions that only focus on reducing IOP may not be beneficial for some glaucoma patients. 


\section{Description of the intervention}

Treating disease by preventing neuronal death or deterioration has been termed neuroprotection (Levin 1999). Different compounds, natural and synthetic, have been reported to have neuroprotective activity. These include antioxidants, N-methyl-D-aspartate (NMDA) receptor antagonists, inhibitors of glutamate release, calcium channel blockers, polyamine antagonists and nitric synthase inhibitors, as well as cannabinoids, aspirin, melatonin and vitamin B-12 (Neacsu 2003; Neufeld 1998; Weinreb 1999).

Neuroprotection for glaucoma refers to any intervention intended to protect the optic nerve or prevent the death of RGCs. The intervention can operate by affecting cellular factors derived from the optic nerve itself or by eliminating risk factors external to the nerve (for example, reducing IOP). This review will consider oral and topical neuroprotective agents for all patients with OAG regardless of IOP.

Neuroprotection occurs in addition to, and as a separate effect from, lowering IOP. If we consider the lowering of IOP as an indirect approach for neuroprotection, and therefore a treatment for glaucoma, it may be necessary to supplement additional neuroprotective agents (Schwartz 2000; Weinreb 1999). Other neuroprotective interventions include neutralization of the toxicity of risk factors; for example, the use of glutamate receptor antagonists or inhibitors of nitric oxide synthase can be considered as different approaches to neuroprotection (Neufeld 1997).

\section{How the intervention might work}

Glaucoma is now recognized as a neurodegenerative disease associated with long-term progressive RGC death (Bathija 1998; Quigley 1999; Schwartz 1996). Some of the cellular processes that result in the death of RGCs, and are consequently targeted by neuroprotective agents, include (1) the production of external nerve-derived risk factors such as glutamate and nitric oxide (NO), (2) the deprivation of internal trophic (nutritional) factors in the nerve cells, (3) the loss of intracellular self-repair processes and (4) the generation of intracellular destructive processes (Schwartz 2000).

The rationale for treatment is that by acting as pharmacological antagonists, neuroprotective agents can correct the imbalance between cellular death and survival signals, thus preventing RGC death and optic nerve damage. Also, self-repair via neuroprotection may lead to preventing the loss of RGC function by targeting the various processes involved in causing the death of RGCs. Since the loss of RGCs is the terminal process in the pathophysiology of glaucoma, neuroprotection may be helpful in preserving visual function. However, there is still no consensus on what precisely causes glaucomatous optic neuropathy.

\section{Why it is important to do this review}

Glaucoma is a leading cause of permanent blindness worldwide. As a chronic and progressive condition, glaucoma is amenable to treatment in the early stages of disease. As such, many types of interventions have been proposed for the treatment of glaucoma. There is a published Cochrane review of topical treatments for the prevention of progression or onset of glaucomatous optic neuropathy (Vass 2007). This review aims to evaluate the evidence for the effectiveness of neuroprotective agents in treating glaucoma. Consideration of the results of this review may lead health policy planners to improve access to prevention programs for glaucoma. 


\section{Objectives}

The objective of this review was to systematically examine the evidence regarding the effectiveness of neuroprotective agents, either topical or oral, for slowing the progression of $\mathrm{OAG}$ in adults.

\section{Methods}

\section{Criteria for considering studies for this review}

Types of studies-We included randomized controlled trials (RCTs) in the review.

Types of participants-We included trials of adults (age 30 years and older) who had OAG with: (1) at least two reliable visual fields demonstrating visual field loss compatible with glaucomatous damage (on the basis of mean deviation and corrected pattern standard deviation or corrected loss variance of Humphrey or Octopus perimetry) and (2) glaucomatous optic nerve changes.

Types of interventions-We included trials that used topical and oral treatments to prevent RGC death. Such agents included:

1. pharmacological antagonists like memantine that inhibit excitotoxicity by binding to NMDA receptors and preventing excitatory activity;

2. alpha 2 adrenergic agonists like brimonidine;

3. calcium channel blocking agents;

4. delivery of brain derived neurotrophic (BDNF) factor to RGC;

5. antioxidant and free radical scavengers;

6. ginkgo biloba extract;

7. nitric oxide synthetase inhibitor.

We included trials that compared any of the above interventions with placebo or no intervention. We also included trials in which any of the above interventions were compared to one another or different regimens of the same intervention.

\section{Types of outcome measures}

Primary outcomes: The primary outcome for this review was the proportion of participants who developed any progression of visual field loss at five years post intervention follow-up. As a result of longer follow-up, one is more likely to detect the effect of lowering IOP ( AGIS 1994; Nouri-Mahdavi 2004).

\section{Secondary outcomes}

1. Visual acuity: the proportion of participants in each category of visual acuity on the Snellen scale. A 3 line change in visual acuity was considered clinically important. Where visual acuity was measured with a different scale, we planned to convert it to the Snellen scale.

2. Intraocular pressure: differences in mean IOP in the treated group of patients that developed progressive visual field loss and the untreated group of patients that developed progressive visual field loss.

3. Vertical cup-disc ratio: the proportion of participants with asymmetrical vertical cup-disc ratio greater than 0.3 . 
Adverse effects: We reported adverse effects related to the particular treatment reported in the included studies. These included any ocular and systemic side-effects that occurred during the treatment period, tolerability, any abnormal ocular finding or any adverse event. An adverse event is defined as any undesirable event occurring in a participant, whether considered related to the study treatment or not.

Quality of life measures: We planned to summarize any quality of life data reported in the included studies.

Economic data: We planned to summarize any economic data including, but not limited to, cost-effectiveness and cost-benefit analyses reported in the included studies. Economic data include direct costs associated with the treatment follow-up, estimated and calculated per participant, and indirect costs such as transportation and expenses necessary to the medical follow-up.

Follow-up: We included trials with at least five years of follow-up to allow for adequate assessment of the effect of neuroprotection on progression of visual field loss. Secondary outcomes were assessed at different follow-up times as available from included studies.

\section{Search methods for identification of studies}

Electronic searches-We searched the Cochrane Central Register of Controlled Trials (CENTRAL) (which contains the Cochrane Eyes and Vision Group Trials Register) (The Cochrane Library, Issue 4, 2009), MEDLINE (January 1960 to January 2010), EMBASE (January 1980 to January 2010), Latin American and Caribbean Literature on Health Sciences (LILACS) (January 1982 to January 2010) and ClinicalTrials.gov (http:// clinicaltrials.gov). (5 January 2010). There were no language or date restrictions in the search for trials. The electronic databases were last searched on 5 January 2010.

See: Appendices for details of search strategies for CENTRAL (Appendix 1), MEDLINE (Appendix 2), EMBASE (Appendix 3), LILACS (Appendix 4) and ClinicalTrials.gov. (Appendix 5).

Searching other resources-We intended to manually search the reference lists of included studies to identify additional trials. We also planned to use the Science Citation Index to screen through studies that cited the included studies to identify additional trials.

\section{Data collection and analysis}

Selection of studies-Two review authors independently reviewed titles and abstracts resulting from the literature searches according to the inclusion criteria stated above. We classified the abstracts as 'definitely exclude', 'unsure' or 'definitely include'. We obtained full text copies of those in the 'definitely include' or 'unsure' categories and re-assessed for inclusion. We resolved any disagreements through discussion. If necessary, we contacted the authors of studies labelled as 'unsure' for further clarification. For all excluded studies, we documented the reasons for exclusion.

Data extraction and management-There were no studies included in this review, thus we performed no data extraction or analysis. If studies are included in the future, we will follow the methods below:

Two review authors will independently extract the data necessary for analysis from the reports of included studies using data extraction forms developed for this review. We will extract the following data for each study: country of clinical trial, participants age and sex, 
trial design, details of the interventions including doses, route of administration and duration of treatment, follow-up schedule and timing of outcome measurements, participant flow charts and the associated numbers. We will also record details of the methods used to ascertain outcomes. It is anticipated that certain parameters, such as visual field, will be measured by various methods in different trials. We will resolve any discrepancies between the two review authors by discussion. Two review authors will independently check the data before entering it into RevMan 5.

Assessment of risk of bias in included studies-Two review authors will independently assess the included studies for methodological quality according to guidelines set out in Chapter 8 of the Cochrane Handbook for Systematic Reviews of Interventions (Higgins 2008). Methods employed to address the following systematic biases will be considered to determine the methodological quality of each study:

a. Selection bias (sequence generation and allocation concealment): Any method of allocation concealment such as centralized randomization or use of sequential opaque envelopes, which provide reasonable confidence that the allocation sequence was concealed from participating physicians and patients, we will consider to be 'low risk of bias'. If the allocation was based on lists or envelopes or there was no qualifying statement describing allocation, we will label it 'unclear risk of bias'.

b. Masking of participants and care providers with regard to treatment allocation to assess for performance bias.

c. Rates of follow-up, reasons for loss to follow-up and analysis by the principle of intention-to-treat to assess for attrition bias. We will consider a trial to have been analyzed by intention-to-treat if it analyzed patients as randomized and included patients for whom no outcome measurements were made and those who received only part or none of the intended treatment.

d. Masking of outcome assessors will be examined to assess for detection bias.

e. Selective outcome reporting will be examined to assess for reporting bias.

We will resolve any disagreement between the review authors through discussion. If any of the included studies are categorized as 'unclear' after reading the original report, we will contact the authors of the studies for additional information.

Measures of treatment effect-We will perform data analysis according to the guidelines in Chapter 9 of the Cochrane Handbook for Systematic Reviews of Interventions (Deeks 2008). We will summarize the dichotomous outcomes using risk ratios. We will summarize continuous outcomes as a weighted mean difference. We will use standardized mean difference to summarize outcomes measured on different scales.

Unit of analysis issues-The unit of analysis will be the individual. For studies that randomized each eye of each participant independently, the unit of analysis will be the eye and we will document the unit of analysis.

Dealing with missing data-We will contact primary investigators of trials for missing data.

Assessment of heterogeneity-We will assess clinical heterogeneity qualitatively before performing statistical tests. If the participants in the included trials differed in any major or obvious way, we will take note and a decision will be made whether or not to 
perform a meta-analysis. We will examine the study characteristics and symmetry of the forest plots. We will interpret a poor degree of overlap in the confidence intervals of the studies as the presence of statistical heterogeneity. The effect estimates across studies will be formally tested for inconsistency using the $\mathrm{Chi}^{2}$ test and $\mathrm{I}^{2}$ statistic. If the $\mathrm{I}^{2}$ statistic is greater than $50 \%$, we will consider there to be substantial heterogeneity.

Assessment of reporting biases-We will use a funnel plot to identify publication bias if three or more studies are included.

Data synthesis-If the $\mathrm{I}^{2}$ statistic is less than $50 \%$, we will interpret it as no significant clinical heterogeneity. If there is no forest plot asymmetry, we will combine the effect estimates in a meta-analysis using a random-effects model. We will use a fixed-effects model if there is no statistical or clinical heterogeneity and if the number of trials is fewer than three. If the $\mathrm{I}^{2}$ statistic is greater than $50 \%$ and if there is significant clinical heterogeneity, we will not conduct a meta-analysis. Instead, we will present a tabulated summary, narrative summary or both.

Sensitivity analysis-We will examine the impact of excluding studies of lower methodological quality, unpublished data and industry-funded studies through sensitivity analyses. We will conduct sensitivity analysis to examine whether the summary effect estimate is influenced by any assumptions that have been made during the review.

\section{Results \\ Description of studies}

Results of the search-The electronic searches revealed 1716 articles, abstracts and reviews. We obtained full text copies of 22 potentially relevant references and re-evaluated for inclusion. We also reviewed seven additional articles identified from screening the reference lists of full text articles.

Of the 29 full text articles that were reviewed, none met the inclusion criteria for this review. From these articles: six were not randomized trials; six did not involve patients with OAG or did not limit the study to patients with OAG; two did not compare the interventions of interest for this review and 15 were short-term trials, between two hours and two and a half years, and thus did not meet the five year follow-up period for this review.

Through a search of the ClinicalTrials.gov database, we identified two phase III trials investigating the effects of memantine in patients with chronic glaucoma (NCT00141882; NCT00168350). Both studies were conducted by Allergan, Inc. and are described as randomized, double-masked, placebo-controlled, parallel assignment studies. Data for the first trial were not published, but were reported to show potential beneficial effects by two review papers (Cheung 2008; McKinnon 2008). The results of the second trial failed to corroborate the results of the first trial. Reports of the second trial publicly released by Allergan, Inc. indicated that progression of glaucoma was significantly lower in patients receiving high-dose memantine compared to patients receiving low-dose memantine, but that there was no significant effect compared to patients receiving placebo. These trials are awaiting classification for inclusion in this review because the follow-up times for outcome measurements are unclear.

Excluded studies-See: 'Characteristics of excluded studies' for further details. 


\section{Risk of bias in included studies}

No studies were included in this review; therefore, we performed no risk of bias analysis.

\section{Effects of interventions}

Based on the specific inclusion criteria for this review, we did not identify any evidence for the effect of neuroprotective agents on slowing the progression in patients with OAG.

\section{Discussion}

Glaucoma is understood to be a progressive neurodegenerative disease; therefore, medical therapies that focus directly on protecting the optic nerve and preventing the death of RGCs should play a role in the future of glaucoma treatment. Furthermore, studies have shown that interventions intended only to lower IOP, the most common risk factor for glaucoma progression, are not always effective in preventing visual field loss (Brubaker 1996; Cockburn 1983). Considered by some to be complimentary or alternative therapy (NICE Guidelines), neuroprotective treatment for glaucoma endeavours to preserve vision by preventing, slowing or reversing the death of RGCs. For the purpose of examining the evidence according to this definition of neuroprotection, the scope of this review was limited by the inclusion criteria to identify studies with long-term outcomes directly related to visual field defects or to the optic nerve itself.

The conditions covered by this review were specific to open angle glaucoma. The population of interest was narrowed to patients with OAG and did not include patients with only ocular hypertension; thus, the prevention of glaucoma by neuroprotection was not studied by this review. Furthermore, although the treatment of ocular hypertension is a method commonly used to prevent glaucoma and delay vision loss, it should be considered as a separate or adjunct focus for prevention since glaucoma can occur in the absence of increased IOP (AAO Preferred Practice Pattern).

We defined the primary outcome for this review as the proportion of patients who developed any progression of visual field loss at five years post intervention follow-up. This outcome is consistent with current recommendations for visual function endpoints for ophthalmic studies (Csaky 2008). Although the reduction of IOP has been the outcome of interest in previous research (Danesh-Meyer 2009), it was not the primary focus of this review since lowering IOP alone is not always effective in preventing visual field loss from glaucoma. Mean change in IOP, however, was included as a secondary outcome as it is currently the commonest risk factor for glaucoma disease progression and reduction may be beneficial for some patients (Seong 2009).

The endpoint for the primary outcome of this review was set at five years post intervention in order to assess the long-term effects of neuroprotection. As such we excluded 15 potentially relevant trials, ranging from two hours to two and a half years follow-up. Three of these studies reported results for visual outcomes at follow-up times greater than six months (Drance 1998; Koseki 1999; Sawada 1996).

The study with the longest follow-up time of two and half years was conducted in Japan by Sawada and colleagues (Sawada 1996). It was a randomized, prospective investigation of the effect of oral brovincamine fumarate (Sabromin; $20 \mathrm{mg}$ three times daily) compared to placebo (three times daily). Brovincamine fumarate is a calcium channel blocker. In Sawada's study, 28 participants were allocated to receive either brovincamine or placebo. Visual fields were tested every four months using a Humphrey Field Analyzer, with mean follow-ups of $39.1 \pm 8.7$ months for the treatment group and $37.9 \pm 10.1$ months for the placebo group. In reference to visual fields analysis, $6 / 14$ eyes had visual field improvement 
and 8/14 had no improvement at all. In the control group, 12/14 had no visual fields changes and $2 / 14$ had an increased visual field loss. This study reported a beneficial effect of brovincamine on visual field in some patients with NTG; however, the study was not able to provide a definitive conclusion due to the small number of participants included in the trial (14 in the brovincamine-treated group and 14 in the placebo-treated group). We contacted the lead author of this study and he informed us that data for longer follow-up times were not collected since brovincamine became unavailable in Japan.

In the study by Koseki et al. (Koseki 1999), the effect of oral brovincamine on further deterioration of the visual field in patients with NTG was investigated. Patients with IOP less than $15 \mathrm{mmHg}$ were randomly assigned to a group receiving oral brovincamine (20 $\mathrm{mg}$ three times daily) or to an untreated control group for two years. This study reported that oral brovincamine may retard further visual field deterioration in patients with NTG who have low to normal IOP; however, the study had a small group of patients enrolled in the study (22 NTG patients in the brovincamine group and 26 in the control group). The authors comment that the slightly better visual field performance in the brovincamine group during the study period may have been attributed to an improvement in cerebral function caused by cerebral vasodilatation rather than a reflection of protection from further glaucomatous damage.

The effects of betaxolol, timolol and pilocarpine on visual functions in patients with OAG were examined in the third excluded study with follow-up longer than six months (Drance 1998). In total, 68 patients were randomized to receive one of the three treatments and visual outcomes were measured after two years follow-up. No significant difference was reported for visual field effects between the treatment groups. The author did note that although all three treatments were effective in reducing IOP, there was dissociation between reduction of IOP and protection of visual function.

Two potentially relevant phase III trials assessing the effects of memantine in patients with chronic glaucoma were identified during this review (NCT00141882; NCT00168350). Memantine, by blocking N-methyl-D-aspartate (NMDA) glutamate receptors that may play a role in RGC death, has been theorized to be a promising neuroprotective agent for the treatment of glaucoma (Levin 2008; Lipton 2003). Positive results from preclinical data and the first trial suggested a possible clinical benefit of memantine (Hare 2009; Ju 2009; Zhong 2007); although, the second phase III trial did not support this reasoning.

The aim of our systematic review was to summarize the evidence related to the effectiveness of different topical and oral neuroprotective agents for treating OAG in adults. Thus far, our review did not identify any clinical trials to establish evidence for neuroprotective benefits on visual field loss progression in OAG.

\section{Authors' conclusions}

\section{Implications for practice}

Recently, there has been a growing interest for using neuroprotective drugs for the treatment of glaucoma. Neuroprotective agents such as (1) pharmacological-antagonists that inhibit excitotoxicity by activation, and N-methyl D-aspartate (NMDA) receptors like memantine; (2) alpha 2 adrenergic agonists like brimonidine; (3) calcium channel blocking agents; (4) deliverers of brain derived neurotrophic (BDNF) factor to RGCs; (5) antioxidants and free radical scavengers; (6) ginkgo biloba extract and (7) nitric oxide synthetase inhibitors have shown promise in preventing or slowing RGC death in preclinical studies. At this time, however, it has not been shown that topical or oral neuroprotective agents are effective in preventing RGC death or in preserving the visual field in patients with OAG. 


\section{Implications for research}

Although a fair amount of cellular and animal research has been completed, clinical research on the neuroprotective effects of oral and topical medical therapy for OAG in adults is needed to provide evidence, if there is any, of a protective effect. Studies should be designed to measure clinically meaningful outcomes, such as progression of visual field loss, in order to guide clinical practice (Osborne 2009). Further efforts should be directed towards investigating long-term visual field preservation with neuroprotective drugs since OAG is a chronic, progressive disease. However, in light of the non-significant findings reported from an expensive and time-consuming phase III trial of memantine, it is doubtful that another long-term trial on neuroprotection will be undertaken.

Another complication in studying the clinical efficacy of neuroprotective agents for glaucoma is that current methodologies used to detect RGC death may not be sufficiently sensitive to show the effect of neuroprotection. Perhaps the ability to prove the efficacy of a neuroprotective drug will depend on the ability to develop and validate new endpoints related to quantitative morphological methods of assessing the retinal ganglion cell layer. The use of sophisticated optical instrumentation and new methodologies to detect cellular events early in the disease process, such as real-time in vivo imaging of an apoptotic event (termed detection of apoptosing retinal cell or DARC), may be useful quantitative measurements to assess neuroprotection in glaucoma patients.

\section{Acknowledgments}

We thank Dr. Roberta Scherer, Dr. Jayter Silva de Paula and Dr. Maria de Lourdes Veronesse Rodrigues for their comments on this review. We also acknowledge Swaroop Vedula at the Cochrane Eyes and Vision Group US Project which is funded by Contract N01-EY-2-1003, National Eye Institute, National Institutes of Health, USA and Anupa Shah for their assistance. We thank Iris Gordon for creating and executing the search strategies.

Sources of support

Internal sources

- $\quad$ No sources of support provided

External sources

- Contract N-01-EY-2-1003, National Eye Institute, National Institutes of Health, USA

\section{References to studies}

\section{Excluded studies}

Alm 2004. Alm A, Schoenfelder J, McDermott J. A 5-year, multicenter, open-label, safety study of adjunctive latanoprost therapy for glaucoma. Archives of Ophthalmology. 2004; 122(7):957-65. [PubMed: 15249358]

Anderson 2003. Anderson DR, Drance SM, Schulzer M. The Collaborative Normal-Tension Glaucoma Study Group. Factors that predict the benefit of lowering intraocular pressure in normal tension glaucoma. American Journal of Ophthalmology. 2003; 136(5):820-9. [PubMed: 14597032]

Blumenthal 2001. Blumenthal EZ, Weinreb RN. Assessment of the retinal nerve fiber layer in clinical trials of glaucoma neuroprotection. Survey of Ophthalmology. 2001; 45(Suppl 3):S305-12. [PubMed: 11377454]

Cantor 1997. Cantor LB, Burke J. Brimonidine. Expert Opinion on Investigational Drugs. 1997; 6(8): 1063-83. [PubMed: 15989664]

Cellini 1999. Cellini M, Rossi A, Moretti M. The use of polyunsaturated fatty acids in ocular hypertension. A study with blue-on-yellow perimetry. Acta Ophthalmologica Scandinavica. 1999; 77(Suppl 229):54-5. 
Changhua 2003. Changhua Y, Youqin J. A clinical study of the neuroprotection effect of Erigeron Breviscapus Hand-Mazz on glaucomatous patient eyes. Chinese Ophthalmic Research. 2003; 21(3):307-11.

Chen 2006. Chen CL, Tseng HY, Wu KY. Rescula as an alternative therapy for beta-blockers with long-term drift effect in glaucoma patients. Kaohsiung Journal of Medical Sciences. 2006; 22(6): 266-70. [PubMed: 16793563]

CNTGS 1998. Collaborative Normal-Tension Glaucoma Study Group. Comparison of glaucomatous progression between untreated patients with normal-tension glaucoma and patients with therapeutically reduced intraocular pressures. American Journal of Ophthalmology. 1998; 126(4):487-97. [PubMed: 9780093] Collaborative Normal-Tension Glaucoma Study Group. Natural history of normal-tension glaucoma. Ophthalmology. 2001; 108(2):247-53. [PubMed: 11158794] Collaborative Normal-Tension Glaucoma Study Group. The effectiveness of intraocular pressure reduction in the treatment of normal-tension glaucoma. American Journal of Ophthalmology. 1998; 126(4):498-505. [PubMed: 9780094]

Cohen 2005. Cohen JS, Khatana AK, Greff LJ. Evolving paradigms in the medical treatment of glaucoma. International Ophthalmology. 2005; 25(5-6):253-65. [PubMed: 16532287]

Drance 1998. Drance SM. A comparison of the effects of Betaxolol, Timolol, and Pilocarpine on visual function in patients with open-angle glaucoma. Journal of Glaucoma. 1998; 7(4):247-52. [PubMed: 9713782]

EMGT 2002. Erb C. Early Manifest Glaucoma Trial update 2004. Der Ophthalmologe: Zeitschrift Der Deutschen Ophthalmologischen Gesellschaft. 2005; 102(3):219-21. [PubMed: 15700191] * Heij1 A, Leske MC, Bengtsson B, Hyman L, Bengtsson B, Hussein M. Early Manifest Glaucoma Trial Group. Reduction of intraocular pressure and glaucoma progression: results from the Early Manifest Glaucoma Trial. Archives of Ophthalmology. 2002; 120(10):1268-79. [PubMed: 12365904] Leske MC, Heijl A, Hussein M, Bengtsson B, Hyman L, Komaroff E. Early Manifest Glaucoma Trial Group. Factors for glaucoma progression and the effect of treatment. Archives of Ophthalmology. 2003; 121(1):48-56. [PubMed: 12523884]

Evans 2003. Evans DW, Hosking SL, Gherghel D, Bartlett JD. Contrast sensitivity improves after brimonidine therapy in primary open angle glaucoma: a case for neuroprotection. The British Journal of Ophthalmology. 2003; 87(12):1463-5. [PubMed: 14660453]

Harris 1995. Harris A, Spaeth GL, Sergott RC, Katz LJ, Cantor LB, Martin BJ. Retrobulbar arterial hemodynamic effects of betaxolol and timolol in normal-tension glaucoma. American Journal of Ophthalmology. 1995; 120(2):168-75. [PubMed: 7639300]

Harris 1999. Harris A, Arend O, Kagemann L, Garrett M, Chung HS, Martin B. Dorzolamide, visual function and ocular hemodynamics in normal-tension glaucoma. Journal of Ocular Pharmacology \& Therapeutics. 1999; 15(3):189-97. [PubMed: 10385127]

Hoyng 2002. Hoyng PF, Kitazawa Y. Medical treatment of normal tension glaucoma. Survey of Ophthalmology. 2002; 47(Suppl 1):S116-24. [PubMed: 12204707]

Iester 2004. Iester M, Perdicchi A, Venturino G, Rolando M, Traverso CE, Leonardi E, et al. Shortterm effects of Bimatoprost in glaucoma patients from an outpatient clinic. Journal of Ocular Pharmacology \& Therapeutics. 2004; 20(5):393-400. [PubMed: 15650514]

Inan 2003. Inan UU, Ermis SS, Yucel A, Ozturk F. The effects of latanoprost and brimonidine on blood flow velocity of the retrobulbar vessels: a 3-month clinical trial. Acta Ophthalmologica Scandinavica. 2003; 81(2):155-60. [PubMed: 12752054]

Kass 1989. Kass MA. Timolol treatment prevents or delays glaucomatous visual field loss in individuals with ocular hypertension: a five-year, randomized, double-masked, clinical trial. Transactions of the American Ophthalmological Society. 1989; 87:598-618. [PubMed: 2562546]

Kjellgren 1995. Kjellgren D, Douglas G, Mikelberg FS, Drance SM, Alm A. The short-time effect of latanoprost on the intraocular pressure in normal pressure glaucoma. Acta Ophthalmologica Scandinavica. 1995; 73(3):233-6. [PubMed: 7493234]

Koseki 1999. Koseki N, Araie M, Yamagami J, Shirato S, Yamamoto S. Effects of oral brovincamine on visual field damage in patients with normal-tension glaucoma with low-normal intraocular pressure. Journal of Glaucoma. 1999; 8(2):117-23. [PubMed: 10209728]

Krupin 2007. Krupin T. A clinical trial studying neuroprotection in low-pressure glaucoma. Eye. 2007; 21(Suppl 1):S51-4.Krupin T. Special considerations in low-tension glaucoma. Canadian Journal 
of Ophthalmology. 2007; 42(3):414-7. [PubMed: 17508037] Krupin, T. Study of Medical Treatment of Low-Pressure (Normal Tension) Glaucoma. http://clinicaltrials.gov/ct2/show/ NCT00317577

Liu 2002. Liu CJ, Ko YC, Cheng CY, Chiu AW, Chou JC, Hsu WM, et al. Changes in intraocular pressure and ocular perfusion pressure after latanoprost $0.005 \%$ or brimonidine tartrate $0.2 \%$ in normal-tension glaucoma patients. Ophthalmology. 2002; 109(12):2241-7. [PubMed: 12466165]

Mastropasqua 1998. Mastropasqua L, Ciancaglini M, Carpineto P, Verdesca G, Ciafre M, Costagliola C. The effect of $1 \%$ apraclonidine on visual field parameters in patients with glaucoma and ocular hypertension. Annals of Ophthalmology-Glaucoma. 1998; 30(1):41-5.

McCarty 2003. McCarty TM, Hardten DR, Anderson NJ, Rosheim K, Samuelson TW. Evaluation of neuroprotective qualities of brimonidine during LASIK. Ophthalmology. 2003; 110(8):1615-25. [PubMed: 12917182]

O'Donoghue 2000. O'Donoghue EP. The UK and Ireland Latanoprost Study Group. A comparison of latanoprost and dorzolamide in patients with glaucoma and ocular hypertension: A 3 month, randomised study. British Journal of Ophthalmology. 2000; 84(6):579-82. [PubMed: 10837379]

Pfeiffer 2002. Pfeiffer N. A comparison of the fixed combination of latanoprost and timolol with its individual components. Graefes Archive for Clinical \& Experimental Ophthalmology. 2002; 240(11):893-9.

Robin 1993. Robin AL. Effect of topical apraclonidine on the frequency of intraocular pressure elevations after combined extracapsular cataract extraction and trabeculectomy. Ophthalmology. 1993; 100(5):628-33. [PubMed: 8098520]

Rulo 1996. Rulo AH, Greve EL, Geijssen HC, Hoyng PF. Reduction of intraocular pressure with treatment of latanoprost once daily in patients with normal-pressure glaucoma. Ophthalmology. 1996; 103(8):1276-82. [PubMed: 8764799]

Sawada 1996. Sawada A, Kitazawa Y, Yamamoto T, Okabe I, Ichien K. Prevention of visual field defect progression with Brovincamine in eyes with normal-tension glaucoma. Ophthalmology. 1996; 103(2):283-8. [PubMed: 8594515]

\section{Studies awaiting classification}

NCT00141882. NCT00141882. [accessed 13 November 2009] Memantine in Patients With Chronic Glaucoma. clinicaltrials.gov/ct2/show/NCT00141882Unpublished data only

NCT00168350. NCT00168350. [accessed 13 November 2009] Memantine in Patients With Chronic Glaucoma. clinicaltrials.gov/ct2/show/NCT00168350Unpublished data only

\section{Other references}

\section{Additional references}

AAO Preferred Practice Pattern. American Academy of Ophthalmology. Primary open-angle glaucoma, preferred practice pattern. San Francisco: American Academy of Ophthalmology; 2005. Available at: www.aao.org/ppp

AGIS 1994. Advanced Glaucoma Intervention Study. 2. Visual field test scoring and reliability. Ophthalmology. 1994; 101(8):1445-55. [PubMed: 7741836]

Armaly 1980. Armaly MF, Krueger DE, Maunder L, Becker B, Hetherington J Jr, Kolker AE, et al. Biostatistical analysis of the collaborative glaucoma study. I. Summary report of the risk factors for glaucomatous visual-field defects. Archives of Ophthalmology. 1980; 98(12):2163-71. [PubMed: 7447768]

Bathija 1998. Bathija R, Gupta N, Zangwill L, Weinreb RN. Changing definition of glaucoma. Journal of Glaucoma. 1998; 7(3):165-9. [PubMed: 9627855]

Bonomi 2002. Bonomi L. Epidemiology of angle-closure glaucoma. Acta Ophthalmologica Scandinavica. 2002; 80(Suppl 236):11-3. [PubMed: 11906297]

Brubaker 1996. Brubaker RF. Delayed functional loss in glaucoma. LII Edward Jackson Memorial Lecture. American Journal of Ophthalmology. 1996; 121(5):473-83. [PubMed: 8610790] 
Cheung 2008. Cheung W, Guo L, Cordeiro MF. Neuroprotection in glaucoma: drug-based approaches. Optometry \& Vision Science. 2008; 85(6):406-16. [PubMed: 18521010]

Cockburn 1983. Cockburn DM. Does reduction of intraocular pressure (IOP) prevent visual field loss in glaucoma? American Journal of Optometry and Physiological Optics. 1983; 60(8):705-11. [PubMed: 6624870]

Csaky 2008. Csaky KG, Richman EA, Ferris FL 3rd. Report from the NEI/FDA Ophthalmic Clinical Trial Design and Endpoints Symposium. Investigative Ophthalmology \& Visual Science. 2008; 49(2):479-89. [PubMed: 18234989]

Danesh-Meyer 2009. Danesh-Meyer HV, Levin LA. Neuroprotection: extrapolating from neurologic diseases to the eye. American Journal of Ophthalmology. 2009; 148(2):186-91. [PubMed: 19464671]

Deeks 2008. Deeks, JJ.; Higgins, JPT.; Altman, DG.; Higgins, JPT.; Green, S., editors. Cochrane Handbook for Systematic Reviews of Interventions Version 5.0.1. The Cochrane Collaboration; 2008. Chapter 9: Analysing data and undertaking meta-analyses. (updated September 2008)Available from www.cochrane-handbook.org

Foster 2000. Foster PJ, Wong JS, Wong E, Chen FG, Machin D, Chew PT. Accuracy of clinical estimates of intraocular pressure in Chinese eyes. Ophthalmology. 2000; 107(10):1816-21. [PubMed: 11013179]

Garway-Heath 1998. Garway-Heath DF, Ruben ST, Viswanathan A, Hitchings RA. Vertical cup/disc ratio in relation to optic disc size: its value in the assessment of the glaucoma suspect. British Journal of Ophthalmology. 1998; 82(10):1118-24. [PubMed: 9924296]

Glanville 2006. Glanville JM, Lefebvre C, Miles JN, Camosso-Stefinovic J. How to identify randomized controlled trials in MEDLINE: ten years on. Journal of the Medical Library Association. 2006; 94(2):130-6. [PubMed: 16636704]

Gupta 1997. Gupta N, Weinreb RN. New definitions of glaucoma. Current Opinion in Ophthalmology. 1997; 8(2):38-41. [PubMed: 10168355]

Hare 2009. Hare WA, Wheeler L. Experimental glutamatergic excitotoxicity in rabbit retinal ganglion cells: block by memantine. Investigative Ophthalmology \& Visual Science. 2009; 50(6):2940-8. [PubMed: 19136701]

Hauser 2006a. Hauser MA, Allingham RR, Linkroum K, Wang J, LaRocque-Abramson K, Figueiredo D, et al. Distribution of WDR36 DNA sequence variants in patients with primary open-angle glaucoma. Investigative Ophthalmology \& Visual Science. 2006; 47(6):2542-6. [PubMed: 16723468]

Hauser 2006b. Hauser MA, Sena DF, Flor J, Walter J, Auguste J, Larocque-Abramson K, et al. Distribution of optineurin sequence variations in an ethnically diverse population of low-tension glaucoma patients from the United States. Journal of Glaucoma. 2006; 15(5):358-63. [PubMed: 16988596]

Heijl 2002. Heijl A, Leske MC, Bengtsson B, Hyman L, Bengtsson B, Hussein M. Early Manifest Glaucoma Trial Group. Reduction of intraocular pressure and glaucoma progression: results from the Early Manifest Glaucoma Trial. Archives of Ophthalmology. 2002; 120(10):1268-79. [PubMed: 12365904]

Higgins 2008. Higgins, JPT.; Altman, DG.; Higgins, JPT.; Green, S., editors. Cochrane Handbook for Systematic Reviews of Interventions Version 5.0.1. The Cochrane Collaboration; 2008. Chapter 8: Assessing risk of bias in included studies. [updated September 2008]Available from www.cochrane-handbook.org

Hunter 2005. Hunter DJ. Gene-environment interactions in human diseases. Nature Reviews Genetics. 2005; 6(4):287-98.

Ju 2009. Ju WK, Kim KY, Angert M, Duong-Polk KX, Lindsey JD, Ellisman MH, et al. Memantine blocks mitochondrial OPA1 and cytochrome c release and subsequent apoptotic cell death in glaucomatous retina. Investigative Ophthalmology \& Visual Science. 2009; 50(2):707-16. [PubMed: 18936150]

Kamal 1998. Kamal D, Hitchings R. Normal tension glaucoma - a practical approach. British Journal of Ophthalmology. 1998; 82(7):835-40. [PubMed: 9924383] 
Levin 1999. Levin LA. Direct and indirect approaches to neuroprotective therapy of glaucomatous optic neuropathy. Survey of Ophthalmology. 1999; 43(Suppl 1):S98-101. [PubMed: 10416753]

Levin 2008. Levin LA, Peeples P. History of neuroprotection and rationale as a therapy for glaucoma. American Journal of Managed Care. 2008; 14(1 Suppl):S11-4. [PubMed: 18284310]

Lipton 2003. Lipton SA. Possible role for memantine in protecting retinal ganglion cells from glaucomatous damage. Survey of Ophthalmology. 2003; 48(Suppl 1):S38-46. [PubMed: 12852433]

McKinnon 2008. McKinnon SJ, Goldberg LD, Peeples P, Walt JG, Bramley TJ. Current management of glaucoma and the need for complete therapy. American Journal of Managed Care. 2008; 14(1 Suppl):S20-7. [PubMed: 18284312]

Neacsu 2003. Neacsu A, Oprean C, Curea M, Tuchila G, Trifu M. Neuroprotection with carotenoids in glaucoma. Oftalmologia. 2003; 59(4):70-5. [PubMed: 15083692]

Neufeld 1997. Neufeld AH, Hernandez MR, Gonzalez M. Nitric oxide synthase in the human glaucomatous optic nerve head. Archives of Ophthalmology. 1997; 115(4):497-503. [PubMed: 9109759]

Neufeld 1998. Neufeld AH. New conceptual approaches for pharmacological neuroprotection in glaucomatous neuronal degeneration. Journal of Glaucoma. 1998; 7(6):434-8. [PubMed: 9871868]

NICE Guidelines. National Collaborating Centre for Acute Care. [accessed Nov 2009] Glaucoma: Diagnosis and management of chronic open angle glaucoma and ocular hypertension. National Institute for Health and Clinical Excellence guideline. Apr. 2009 http://www.nice.org.uk

Nouri-Mahdavi 2004. Nouri-Mahdavi K, Hoffman D, Coleman AL, Liu G, Li G, Gaasterland D, et al. Predictive factors for glaucomatous visual field progression in the Advanced Glaucoma Intervention Study. Ophthalmology. 2004; 111(9):1627-35. [PubMed: 15350314]

Osborne 2003. Osborne NN, Chidlow G, Wood J, Casson R. Some current ideas on the pathogenesis and the role of neuroprotection in glaucomatous optic neuropathy. European Journal of Ophthalmology. 2003; 13(Suppl 3):S19-26. [PubMed: 12749673]

Osborne 2009. Osborne NN. Recent clinical findings with memantine should not mean that the idea of neuroprotection in glaucoma is abandoned. Acta Ophthalmologica. 2009; 87(4):450-4. [PubMed: 19141144]

Quigley 1999. Quigley HA. Neuronal death in glaucoma. Progress in Retinal and Eye Research. 1999; 18(1):39-57. [PubMed: 9920498]

Quigley 2001. Quigley HA, West SK, Rodriguez J, Munoz B, Klein R, Snyder R. The prevalence of glaucoma in a population-based study of Hispanic subjects: Proyecto VER. Archives of Ophthalmology. 2001; 119(12):1819-26. [PubMed: 11735794]

Quigley 2006. Quigley HA. Number of people with glaucoma worldwide in 2010 and 2020. British Journal of Ophthalmology. 2006; 90(3):262-7. [PubMed: 16488940]

Ramakrishnan 2003. Ramakrishnan R, Nirmalan PK, Krishnadas R, Thulasiraj RD, Tielsch JM, Katz $\mathrm{J}$, et al. Glaucoma in a rural population of southern India: the Aravind comprehensive eye survey. Ophthalmology. 2003; 110(8):1484-90. [PubMed: 12917161]

Resnikoff 2004. Resnikoff S, Pascolini D, Etya'ale D, Kocur I, Pararajasegaram R, Pokharel GP, et al. Global data on visual impairment in the year 2002. Bulletin of the World Health Organization. 2004; 82(11):844-51. [PubMed: 15640920]

Schwartz 1996. Schwartz M, Belkin M, Yoles E, Solomon A. Potential treatment modalities for glaucomatous neuropathy: neuroprotection and neuroregeneration. Journal of Glaucoma. 1996; 5(6):427-32. [PubMed: 8946301]

Schwartz 2000. Schwartz M, Yoles E. Neuroprotection: a new treatment modality for glaucoma? Current Opinion in Ophthalmology. 2000; 11(2):107-11. [PubMed: 10848215]

Seong 2009. Seong GJ, Rho SH, Kim CS, Moon JI, Kook MS, Kim YY, et al. Potential benefit of intraocular pressure reduction in normal-tension glaucoma in South Korea. Journal of Ocular Pharmacology \& Therapeutics. 2009; 25(1):91-6. [PubMed: 19232005]

Shields 1996. Shields, MB.; Ritch, R.; Krupin, T. Classification of the Glaucomas. St. Louis: Mosby; 1996. 
Tielsch 1991. Tielsch JM, Sommer A, Katz J, Royall RM, Quigley HA, Javitt J. Racial variations in the prevalence of primary open-angle glaucoma. The Baltimore Eye Survey. Journal of the American Medical Association. 1991; 266(3):369-74. [PubMed: 2056646]

Vass 2007. Vass C, Hirn C, Sycha T, Findl O, Sacu S, Bauer P, Schmetterer L. Medical interventions for primary open angle glaucoma and ocular hypertension. Cochrane Database of Systematic Reviews. 2007; (4):Art. No.: CD003167.10.1002/14651858.CD003167.pub3

Weinreb 1999. Weinreb RN, Levin LA. Is neuroprotection a viable therapy for glaucoma? Archives of Ophthalmology. 1998; 117(11):1540-4. [PubMed: 10565524]

Zhong 2007. Zhong L, Bradley J, Schubert W, Ahmed E, Adamis AP, Shima DT, et al. Erythropoietin promotes survival of retinal ganglion cells in DBA/2J glaucoma mice. Investigative Ophthalmology \& Visual Science. 2007; 48(3):1212-8. [PubMed: 17325165]

\section{Appendices}

\section{CENTRAL search strategy}

\#1 MeSH descriptor Glaucoma

\#2 glaucoma*

\#3 (\#1 OR \#2)

\#4 MeSH descriptor Neuroprotective Agents

\#5 neuroprotect*

\#6 MeSH descriptor Retinal Ganglion Cells

\#7 ganglion near cell*

\#8 retina* near cell*

\#9 RGC

\#10 MeSH descriptor Optic Nerve Diseases

\#11 optic near neuropath*

\#12 MeSH descriptor Memantine

\#13 memantine

\#14 (\#4 OR \#5 OR \#6 OR \#7 OR \#8 OR \#9 OR \#10 OR \#11 OR \#12 OR \#13)

\#15 (\#3 AND \#14)

\section{MEDLINE search strategy}

1. randomized controlled trial.pt.

2. (randomized or randomised).ab,ti.

3. placebo.ab,ti.

4. dt.fs.

5. randomly.ab,ti.

6. trial.ab,ti.

7. groups.ab,ti.

8. or/1-7 

9. exp animals/
10. exp humans/
11. 9 not (9 and 10)
12. 8 not 11
13. exp glaucoma/
14. glaucoma $\$$.tw.
15. or/13-14
16. exp neuroprotective agents/
17. neuroprotect $\$$.tw.
18. exp retinal ganglion cells/
19. (ganglion adj2 cell\$).tw.
20. (retina $\$$ adj2 cell\$).tw.
21. RGC.tw.
22. exp optic nerve disease/
23. (optic adj2 neuropath\$).tw.
24. Memantine/
25. memantine.tw.
26. or/16-25
27. 15 and 26
28. 12 and 27

The search filter for trials at the beginning of the MEDLINE strategy is from the published paper by Glanville et al (Glanville 2006).

\section{EMBASE search strategy}

1. exp randomized controlled trial/

2. exp randomization/

3. $\exp$ double blind procedure/

4. exp single blind procedure/

5. random $\$ . t w$.

6. or $/ 1-5$

7. (animal or animal experiment).sh.

8. human.sh.

9. 7 and 8

10. 7 not 9

11. 6 not 10

12. exp clinical trial/ 
13. (clin $\$$ adj3 trial\$).tw.

14. (( $\operatorname{singl} \$$ or doubl\$ or trebl\$ or tripl\$) adj3 (blind $\$$ or mask $\$)$ ).tw.

15. exp placebo/

16. placebo\$.tw.

17. random $\$$.tw.

18. exp experimental design/

19. exp crossover procedure/

20. exp control group/

21. exp latin square design/

22. or $/ 12-21$

23. 22 not 10

24. 23 not 11

25. exp comparative study/

26. exp evaluation/

27. exp prospective study/

28. (control\$ or prospectiv\$ or volunteer\$).tw.

29. or $/ 25-28$

30. 29 not 10

31. 30 not (11 or 23 )

32. 11 or 24 or 31

33. exp glaucoma/

34. glaucoma $\$ . t w$.

35. or $/ 33-34$

36. exp neuroprotective agent/

37. neuroprotect\$.tw.

38. exp retinal ganglion cell/

39. (ganglion adj2 cell\$).tw.

40. (retina $\$$ adj 2 cell\$).tw.

41. RGC.tw.

42. exp optic nerve disease/

43. (optic adj2 neuropath\$).tw.

44. Memantine/

45. memantine.tw.

46. or $/ 36-45$

47. 35 and 46 
48. 32 and 47

\section{LILACS search strategy \\ glaucoma \$ and neuroprotect\$ or memantine}

\section{ClinicalTrials.gov search strategy}

glaucoma and neuroprotection

glaucoma and memantine 